\title{
Rates and predictors of consideration for adjuvant radiotherapy among high-risk breast cancer patients: a cohort study
}

\author{
Stanimira Krotneva $\cdot$ Kristen Reidel $\cdot$ \\ Mohammed Nassif • Nora Trabulsi • \\ Nancy Mayo $\cdot$ Robyn Tamblyn $\cdot$ Ari N. Meguerditchian
}

Received: 8 July 2013/Accepted: 8 July 2013/Published online: 24 July 2013

(c) The Author(s) 2013. This article is published with open access at Springerlink.com

\begin{abstract}
Radiotherapy (RT) after breast conserving surgery (BCS) represents the standard for local control of breast cancer (BC). However, variations in practice persist. We aimed to characterize the rate of RT consideration (or referral) after BCS and identify predictors in Quebec, Canada, where universal health insurance is in place. A historical prospective cohort study using the provincial hospital discharge and medical services databases was conducted. All women with incident, non-metastatic BC (stages I-III) undergoing BCS (1998-2005) were identified. Odds ratios (ORs) and $95 \%$ confidence intervals (CIs) for RT consideration were estimated with a generalized estimating equations regression model, adjusting for clustering of patients within physicians. Of the 27,483 women selected, $90 \%$ were considered for RT and $84 \%$ subsequently received it. Relative to women 50-69 years old, younger and older women were less likely to be considered: ORs of 0.82 (95\% CI $0.73-0.93)$ and 0.10 (0.09-0.12), respectively. Emergency room visits and hospitalizations unrelated to $\mathrm{BC}$ were associated with
\end{abstract}

S. Krotneva · K. Reidel · M. Nassif · R. Tamblyn ·

A. N. Meguerditchian $(\bowtie)$

Clinical and Health Informatics Research Group,

McGill University, 1140 Pine Avenue West, Montreal,

QC H3A 1A3, Canada

e-mail: ari.meguerditchian@mcgill.ca

S. Krotneva

e-mail: stanimira.krotneva@mail.mcgill.ca

M. Nassif · N. Trabulsi - A. N. Meguerditchian

Department of Surgery, McGill University, Montreal,

QC, Canada

N. Trabulsi

Department of Surgery, King Abdul-Aziz University, Jeddah,

Saudi Arabia decreased odds of RT consideration: 0.85 (0.76-0.94) and 0.83 (0.71-0.97). Women with regional BC considered for chemotherapy were more likely to be considered for RT: 3.41 (2.83-4.11). RT consideration odds increased by $7 \%$ (OR of 1.07, $95 \%$ CI 1.03-1.10) for every ten additional BCSs performed by the surgeon in the prior year. Social isolation, comorbidities, and greater distance to a referral center lowered the odds. Demographic and clinical patientrelated risk factors, health service use, gaps in other aspects of BC management, and surgeon's experience predicted RT consideration.

Keywords Guidelines - Radiotherapy $\cdot$ Breast cancer $\cdot$ Consideration

$\begin{array}{ll}\text { Abbreviations } & \\ \text { RT } & \text { Radiotherapy } \\ \text { BC } & \text { Breast cancer } \\ \text { BCS } & \text { Breast conserving surgery } \\ \text { CRID } & \text { Designated referral center }\end{array}$

N. Mayo $\cdot$ R. Tamblyn

Department of Epidemiology Biostatistics and Occupational Health, McGill University, Montreal, QC, Canada

N. Mayo $\cdot$ R. Tamblyn

Department of Medicine, McGill University, Montreal, QC, Canada

N. Mayo

School of Physical and Occupational Therapy, McGill

University, Montreal, QC, Canada

A. N. Meguerditchian

Department of Oncology, McGill University, Montreal, QC, Canada 


$\begin{array}{ll}\text { OR } & \text { Odds ratio } \\ \text { CI } & \text { Confidence interval } \\ \text { NCCN } & \text { National comprehensive cancer network } \\ \text { RAMQ } & \text { Régie de l'assurance maladie du Québec } \\ \text { SSI } & \text { Social isolation index } \\ \text { MSSS } & \begin{array}{l}\text { Ministère de la Santé et des Services } \\ \text { sociaux }\end{array} \\ \text { MED-ÉCHO } & \begin{array}{l}\text { Maintenance et exploitation des données } \\ \text { pour l'étude de la clientèle hospitalière }\end{array} \\ \text { IRB } & \text { Institutional review board } \\ \text { CCI } & \text { Charlson comorbidity Index } \\ \text { ER } & \text { Emergency room visit } \\ \text { ICD } & \text { International classification of diseases } \\ \text { DCTD } & \text { Diffused connective tissue disease } \\ \text { COPD } & \text { Chronic obstructive pulmonary disease } \\ \text { GEE } & \text { Generalized estimating equation } \\ \text { CCSRI } & \text { Canadian Cancer Society Research } \\ \text { CIHR } & \text { Institute (CCSRI) } \\ \text { FRSQ } & \text { Canadian Institutes of Health Research } \\ \text { Fonds de la recherche en Santé du Québec }\end{array}$

\section{Introduction}

Variations in quality of care have been documented in every aspect of breast cancer (BC) management, from prevention to follow-up $[8,25,30]$. It is estimated that up to $70 \%$ of $\mathrm{BC}$ patients may not be receiving the proper care for at least one component of their BC treatment [27]. In addition to affecting quality of life and health care costs, these discrepancies have been proven to result in higher recurrence rates and shorter survival [20, 37, 46]. Deviations from best practices in $\mathrm{BC}$ management are not limited to complex cases or difficult treatment schemas; they most often concern basic, well-established evidence-based standards of care [38].

Patients with high-risk non-metastatic $\mathrm{BC}$ who receive radiotherapy (RT) after breast conserving surgery (BCS) achieve significantly better local control $[9,12,16]$. The addition of RT decreases the 5-year BC local recurrence rate from 26 to $7 \%$ [9], with a benefit that persists at 20 years of follow-up [16, 45]. In fact, the combination of BCS and RT has been shown to provide cancer control equivalent to mastectomy [15] and has therefore become the standard method of treatment as it avoids the physiological and psychological impact associated with mastectomy. Consequently, BCS followed by RT has become the standard of care according to guidelines for the management of patients with high-risk non-metastatic BC [32].

Despite this evidence, some high-risk BC patients fail to receive RT after BCS due to a variety of patient, physician, and other factors [9]. A better understanding of the risk factors leading to suboptimal local BC control is needed to address this gap in cancer care quality. The universal health insurance program in the province of Quebec (Canada) provides a unique opportunity to study barriers to optimal health care, confounded to a lesser degree by socio-economic status [14]. To receive RT in Quebec, a patient must be seen by a radiation oncologist working at a designated referral center (CRID) [18]. Failure to receive a referral to a radiation oncologist may reflect lack of patient consideration for RT by the treating physician and thus lack of RT receipt. The primary objectives of the present study were to characterize the rate of guideline-appropriate consideration for RT in women with BC (stages I-III), who underwent BCS between Jan 1, 1998 and Dec 31, 2005 in Quebec and to identify patient- and physician-related factors that predict it.

\section{Population and methods}

Setting and data sources

The source population for this study consisted of Quebec residents, covered by the provincial health insurance plan (RAMQ) ( $>98 \%$ of the province's population of $>7.8$ million). Data for this study was available from 1997 to 2007 and was acquired through anonymous linkage of the following databases: (1) RAMQ's registrants' database, which provides demographic and socioeconomic data including the social isolation index (SSI) [35] for registrants; (2) RAMQ's medical services database, which contains physician fee-for-service claims; and (3) Quebec's hospital abstract discharge database (MED-ÉCHO), which captures data on hospital admissions and discharge diagnoses. MED-ÉCHO is the data source for the Quebec Tumor Registry, which was used to verify that all BC were new incident cases. Appropriate ethical clearances were obtained from the Institutional Review Board (IRB) at McGill University and the Provincial Access to Information Office.

\section{Design and study population}

A historical prospective cohort study design was used. Women $\geq 18$ years of age, which were diagnosed with localized or regional BC in Quebec between Jan 1, 1998 and Dec 31 and underwent BCS within 6 months of diagnosis, were identified from MED-ÉCHO. To identify these women, RAMQ procedure codes (Table 3) corresponding to BCS and primary diagnostic codes [International Classification of Diseases, 9th edition, adapted for Quebec (ICD-9-QC)] corresponding to a diagnosis for localized or regional BC [28] (Table 4) were used. Women entered the cohort in 1998 in order to ensure at least 1 year 
of medical service history prior to the BCS was available for the selected patients. Women with in situ or metastatic $\mathrm{BC}$, those who received a mastectomy, passed away, or became ineligible for medical insurance in the year after diagnosis, were excluded from the study population. Patients from insular or remote northern territories were also excluded (Iles-de-la-Madeleine, Nord-du-Quebec \& Anticosti) on the premise that health care provision in these regions differed too much from other parts of the province, making them outliers.

\section{Assessment of patient and surgeon characteristics}

Patient and surgeon characteristics were assessed for the year prior to the patient's BCS. Age at diagnosis was calculated using the patient's date of birth, provided by the registrants' database. The residence of each patient was classified as rural or urban if the second digit of her postal code was 0 or not, in accordance with Canada Post Corporation delivery service [41]. The driving distance between the centroid of each patient's forward sortation area (first 3 characters of the postal code) and the nearest designated center of excellence for breast care in Quebec [18] was calculated in kilometers (km) using Google Maps. The comorbidity profile of each patient was assessed using the Charlson comorbidity index (CCI), calculated using the Enhanced ICD-9 coding algorithm [36] using the medical services database. The ICD-9 codes for BC were removed from the algorithm index since as all women in the cohort have BC by default. Visits to the emergency room (ER) were determined using RAMQ establishment code " $0 X 7$," corresponding to "emergency department" in the medical services database. The number and type (over-night or day cases) of hospitalizations according to surgery was determined from the MED-ÉCHO database. Conditions contraindicative for RT such as diffused connective tissue disease (DCTD), chronic obstructive pulmonary disease (COPD), or pregnancy were assessed from the medical services database using selected ICD-9 codes or RAMQ procedure codes relating to this condition (Tables 3,4). Chemotherapy consultation and receipt were identified through the presence of claims with RAMQ procedure codes corresponding to either consultation for chemotherapy or treatment in the medical services database up to 4 months after BCS (Table 3 ). The stage of BC was determined using topography and morphology codes in the hospital discharge database as previously published [28].

Surgeon and hospital characteristics included number of BCSs performed prior to the selected woman's surgery. RAMQ procedure codes were used to determine the number and type of BC surgeries from the medical services database (Table 3). Surgeons were classified as either general surgeons (RAMQ specialty code of 24) or "other" surgeons.
Assessment of outcome

RT consideration was ascertained through the presence of claims with RAMQ procedure codes corresponding to either consultation with a radiation oncologist (RAMQ physician specialty code of 30 ) or treatment in the medical services database up to 1 year after diagnosis, as per guideline recommendations [34] (Table 4). It was assumed that if a woman received a consultation for RT but no subsequent treatment, she had been considered for therapy.

\section{Data analysis}

A generalized estimating equation (GEE) model [26] with logit link and exchangeable working correlation structure was constructed to assess the association between predictor variables and RT consideration after taking into account the clustering of patients' characteristics treated by the same physician (i.e., physician was repeated over patients). The distribution was assumed to be binomial. Univariate analysis was performed to assess the unadjusted associations between each predictor and the outcome. Subsequently, all predictors were included in the GEE model. Collinearity between variables was assessed via a Pearson correlation matrix and, as a result, residence was left out of the model due to its correlation (coefficient of $\geq 0.5$ ) with distance to hospital. In addition, interaction terms "considered for chemotherapy" and "cancer stage" were tested based on the premise that having been considered for chemotherapy and patient's BC stage may have influenced RT consideration but were found not to be significant. Subsequently, stepwise selection of significant variables was performed. The working correlation of the final GEE model was 0.030 . All $P$ values are for two-tailed tests with statistical significance defined as $P \leq 0.05$. SAS software (SAS version 9.2, SAS Institute, Inc., Cary, NC) was used for all analyses.

\section{Results}

\section{Patient characteristics}

In total, 42,800 women were diagnosed with incident BC in Quebec between Jan 1, 1998 and Dec 31, 2005. Of these, $15,317(35.8 \%)$ were excluded because they had in situ $(N=4,549)$ or metastatic BC diagnosis $(N=215)$, died $(N=2,443)$ or became ineligible for medical insurance within 1 year of diagnosis $(N=53)$, were treated with mastectomy $(N=5,922)$ or did not have a breast surgery at all $(N=2,075)$, or lived in remote outlier regions $(N=60)$. The remaining 27,483 women comprised the 
Table 1 Baseline demographic and clinical characteristics of patients $(N=27,483)$

\begin{tabular}{ll}
\hline Patient characteristics & Value \\
\hline Age $($ years $)[n(\%)]$ & \\
$\quad<50$ & $6,189(22.6)$ \\
$50-69$ & $14,958(54.5)$ \\
$70-79$ & $4,622(16.8)$ \\
$\geq 80$ & $1,714(6.2)$ \\
Mean $(\mathrm{SD})$ & $59.5(12.5)$ \\
Range & $18-99$ \\
Year of BCS $[n(\%)]$ & \\
$\leq 2000$ & $6,893(25.1)$ \\
$>2001$ & $20,576(74.9)$
\end{tabular}

Stage of tumor $[n(\%)]$

Localized

Regional

SII $[n(\%)]$

Less isolated (values 1-3)

More isolated (values 4-5)

$\mathrm{N} / \mathrm{A}^{\mathrm{a}}$

Residence [ $n(\%)]$

Urban

Rural

Distance to designated radiotherapy center $(\mathrm{km})[n(\%)]$

$<20$

20-49

50-99

$\geq 100$

Mean (SD)

Range

$\mathrm{CCI}^{\mathrm{b}}[n(\%)]$

0

1

2

$3+$

ER visits unrelated to $\mathrm{BC}^{\mathrm{c}}[n(\%)]$

Yes

No

Overnight hospitalizations unrelated to $\mathrm{BC}^{\mathrm{c}}[n(\%)]$

Yes

No

Contraindicated for RT conditions ${ }^{\mathrm{c}}[n(\%)]$

Diffuse diseases of connective tissue

Chronic pulmonary disease

Pregnancy

RT status ${ }^{\mathrm{d}}[n(\%)]$

Had consult and started

Had consult but did not start

Had no consult

Chemotherapy status ${ }^{\mathrm{e}}[n(\%)]$

Had consult and started
$19,901(72.4)$

$7,582(27.6)$

$15,242(55.5)$

$11,345(41.3)$

$896(3.3)$

$22,772(82.9)$

$4,711(17.1)$

Table 1 continued

\begin{tabular}{ll}
\hline Patient characteristics & Value \\
\hline Had consult but did not start & $7,016(25.5)$ \\
No consult & $13,539(49.3)$ \\
Number of BC treating physicians ${ }^{\mathrm{d}}$ & \\
Mean (SD) & $4.2(2.3)$ \\
Range & $1-21$ \\
Surgeon's speciality ${ }^{\mathrm{c}}[n(\%)]$ & \\
General surgery & $27,393(99.7)$ \\
Other surgical specialties $^{\mathrm{c}}$ & $90(0.3)$ \\
Surgeon's case volume & \\
Mean number of BCSs (SD) & $51.3(51.8)$ \\
Range & $0-279$ \\
\hline
\end{tabular}

$S D$ Standard deviation, $B C S$ breast conserving surgery, SII social isolation index, N/A unavailable, $C C I$ Charlson comorbidity index, $E R$ emergency room, $B C$ breast cancer, $R T$ radiotherapy

${ }^{a}$ SII was not available for a small subset of the population

b ICD-9 codes for BC were removed from the coding algorithm for the CCI since as all women in the cohort had BC by default

c Assessed in the year prior to BCS

d Assessed in the year after BCS

e Assessed up to 4 months after BCS

study population. All of these women were diagnosed with non-metastatic BC (stages I-III) and treated with BCS within 6 months of diagnosis. Mean age was 60 years (range: 18-99), $72 \%$ of women had localized BC, $77 \%$ did not have major comorbidities (CCI of 0) (Table 1). Demographically, $83 \%$ of women lived in urban areas, $70 \%$ of women lived within $20 \mathrm{~km}$ from a designated referral center, and $56 \%$ of women were not considered socially isolated (SSI $\leq 3$ ). Less than $1 \%$ of the cohort had DCTD or pregnancy during treatment, while $10 \%$ had COPD. About 6 and $75 \%$ of women had an over-night hospital admission or an ER visit, respectively, both unrelated to their $\mathrm{BC}$ in the year prior to $\mathrm{BCS}$.

$20,615(75.0)$

$4,376(15.9)$

$1,509(5.5)$

$25,974(94.5)$

$71(0.3)$

$2,713(9.9)$

$35(0.1)$

23,205 (84.4)

$1,559(5.7)$

2,719 (9.9)

6,928 (25.2)
Physician characteristics

On average, women saw 4 physicians (range: 1-21) for their BC in the year after their BCS. Of the surgeons who performed this cohort's BCSs, $99 \%$ were general surgeons. The latter performed an average of 52 BCS (range: 0-279) in the prior year.

\section{Use of RT in Quebec}

Overall, 24,764 (90\%) of women with incident, nonmetastatic $\mathrm{BC}$ having undergone $\mathrm{BCS}$ were considered for RT (i.e., received a consultation or referral) within a year. Of those, $84 \%$ subsequently received RT. 
Factors associated with RT consideration

Results of the statistical analysis of factors associated with consideration of postoperative RT are described in Table 2. Relative to the largest age group (50-69 years), odds ratios (ORs) for groups $<50,70-79$, and $\geq 80$ years were 0.82 [confidence interval (CI) $0.73,0.93$ ], 0.55 (0.48, 0.61), and $0.10(0.09,0.12)$, respectively. Relative to those living close to a designated RT center, those living far had a significantly less likely to be considered for RT, OR 0.96 (0.94-0.97) per $20 \mathrm{~km}$ increase in distance. Less socially isolated women (SII of 1-3) were more likely to be considered for RT, OR 1.16 (1.06-1.26) compared to more socially isolated ones (SII of 4-5). Relative to women with CCI of 0 , those with CCI of $\geq 3$ (moderate to severe comorbidities) were less likely to be considered for RT, OR 0.79 (0.62-1.00). Women with overnight hospitalizations or ER visits, both unrelated to $\mathrm{BC}$ in the past year, were also less likely to be considered for RT, compared to those without, OR 0.83 (0.71-0.98) and 0.85 (0.76-0.94), respectively. Women with localized and regional $\mathrm{BC}$ that were considered for chemotherapy were also more likely to be considered for RT: ORs 2.27 (1.96-2.64) and 3.41 (2.83-4.11), respectively. Surgeon's volume of BCS in the previous year significantly predicted RT consideration. A $7 \%$ increase in the odds of being considered for RT was seen for every ten additional BCS performed in the previous year by the treating surgeon: OR 1.07 (1.03-1.10).

\section{Discussion}

In this large population-based study of Quebec women with incident, non-metastatic BC (stages I-III), we found that 1 in 10 women undergoing BCS were not considered for RT. Lack of consideration for RT was associated with age extremes (younger and elderly patients being significantly less likely to be considered), social isolation, CCI, distance from a designated RT center, and certain health service use indicators such as ER visits or hospitalizations in the year before BCS. We also found that gaps in other aspects of BC care, such as lack of consideration for chemotherapy (in patients with stage III disease) or surgeon's volume of BCS were also strongly associated with lack of RT consideration.

A substantial variation in the use of RT after BCS has been reported by existing studies, ranging 57-95\% based on geographical region and study population $[7,11,23$, 44]. However, many of these studies have mostly explored the rate of RT receipt as opposed to rate of RT consideration, omitted physician-related factors [44], have been limited to patients with early-stage BC [11, 47], carcinoma in situ [1, 13], smaller sample sizes [7, 23, 33, 44], included only older patients [39, 40]. The rate of RT receipt observed in this study (84\%) is similar to studies using insured populations. However, less is known about the impact of treatment decisions by the physician on access to RT, especially for young or middle-aged women with locally advanced BC. We found only three studies [3, 33, 44] that evaluated the rate of RT consideration. They reported values in range of 77-94\%, which were consistent with our study.

Older age [2, 11], distance to RT centers [31], rural, isolated, ethnic, or unmarried status [3], and the presence of comorbidities [2] have been consistently reported as a risk factors for RT non-receipt across the literature. However, the link between RT non-consideration and these demographic and clinical factors remains poorly understood. It may reflect a certain level of physician noncompliance with practice guidelines in addition to patients' treatment preferences or patients' barriers to access of health care such as distance, age, or socioeconomic status. We observed that women less than 50 years were less likely to be considered for RT compared to the 50-69 age group, which is concerning since these women have a greater chance of recurrence, longer life-expectancy, and have been shown to be less persistent and adherent to future therapy such as adjuvant hormonal therapy [21]. Younger women with cancer have unique medical, psychosocial, and economic challenges that might be decreasing their odds of consideration for treatments such as RT by some physicians [5]. Further research is required to understand the challenges unique to this population.

Our study found that healthcare service utilization indicators such as overnight hospitalizations and ER visits, both unrelated to $\mathrm{BC}$, in the year before BCS, were associated with a lower chance of being considered for RT after BCS after adjustment for comorbidities. Such indicators might be reflective of additional comorbidities and/or lack of affiliation with a family physician resulting in a lack of continuity and comprehensiveness of care [29]. In addition, a tendency to underestimate comorbidity in claims data has been previously shown [10] and this may have lowered the explanatory power of the CCI index in this study. This may explain why women with such health service utilization indicators were in a worse position for being considered for RT, compared to women without such indicators. Efforts to increase continuity of care may improve treatment outcomes in BC care.

Variations in quality of care have been documented in other aspects of cancer care from prevention to management and follow-up and stem from complex interplay of patient, provider, and institutional factors [8, 25, 30]. In this study, we observed that women with stage III disease that were considered for chemotherapy had stronger odds for RT consideration compared to those not considered for 
Table 2 Patient-related demographic and clinical predictors of radiotherapy consideration

\begin{tabular}{|c|c|c|c|c|c|c|c|c|c|c|}
\hline \multirow[t]{2}{*}{ Predictors } & \multirow{2}{*}{\multicolumn{2}{|c|}{$\%$ considered for $\mathrm{RT}^{\mathrm{a}}$}} & \multirow{2}{*}{\multicolumn{2}{|c|}{ No. of patients }} & \multicolumn{3}{|c|}{ Univariate analysis $^{\mathrm{b}}$} & \multicolumn{3}{|c|}{ Multivariate GEE analysis ${ }^{\mathrm{c}}$} \\
\hline & & & & & OR & $95 \% \mathrm{CI}$ & $P$ & OR & $95 \% \mathrm{CI}$ & $P$ \\
\hline \multicolumn{11}{|l|}{ Age (years) } \\
\hline$<50$ & \multicolumn{2}{|l|}{93.3} & \multicolumn{2}{|c|}{6,189} & 0.97 & $0.86-1.09$ & 0.600 & 0.82 & $0.73-0.93$ & 0.002 \\
\hline $50-69$ & \multicolumn{2}{|l|}{93.6} & \multicolumn{2}{|c|}{14,958} & 1.00 & \multicolumn{2}{|l|}{ Referent } & 1.00 & Referent & \\
\hline $70-79$ & \multicolumn{2}{|l|}{87.9} & \multicolumn{2}{|c|}{4,622} & 0.45 & $0.41-0.50$ & $<0.001$ & 0.55 & $0.48-0.61$ & $<0.001$ \\
\hline$\geq 80$ & \multicolumn{2}{|l|}{53.9} & \multicolumn{2}{|c|}{1,714} & 0.07 & $0.07-0.08$ & $<0.001$ & 0.10 & $0.09-0.12$ & $<0.001$ \\
\hline \multicolumn{11}{|l|}{ Social isolation index } \\
\hline Less isolated (values $1-3$ ) & \multicolumn{2}{|l|}{91.2} & \multicolumn{2}{|c|}{15,242} & 1.28 & $1.18-1.39$ & $<0.001$ & 1.16 & $1.06-1.26$ & $<0.001$ \\
\hline More isolated (values 4-5) & \multicolumn{2}{|l|}{89.1} & \multicolumn{2}{|c|}{11,345} & 1.00 & Referent & 0.006 & 1.00 & Referent & \\
\hline N/A & 84.2 & & & & 0.65 & $0.54-0.79$ & $<0.001$ & 0.74 & $0.61-0.89$ & 0.001 \\
\hline Charlson comorbidity index & & & & & & & & & & \\
\hline 0 (none) & 91.2 & & 20 & & 1.00 & Referent & & 1.00 & Referent & \\
\hline 1 & 88.0 & & & & 0.71 & $0.64-0.78$ & $<0.001$ & 0.93 & $0.84-1.04$ & 0.191 \\
\hline 2 & 86.5 & & & & 0.66 & $0.56-0.77$ & $<0.001$ & 0.86 & $0.71-1.04$ & 0.123 \\
\hline$\geq 3$ (moderate or severe) & 83.0 & & & & 0.46 & $0.37-0.57$ & $<0.001$ & 0.79 & $0.62-1.00$ & 0.046 \\
\hline Hospitalizations, unrelated to $\mathrm{BC}$ & in year & ore BCS & & & & & & & & \\
\hline Over-night hospitalization(s) & 83.0 & & & & 0.51 & $0.44-0.59$ & $<0.001$ & 0.83 & $0.71-0.98$ & 0.024 \\
\hline No over-night hospitalizations & 90.5 & & 25 , & & 1.00 & Referent & & 1.00 & Referent & \\
\hline ER visits, unrelated to $B C$, in ye & before & & & & & & & & & \\
\hline Yes & 86.9 & & & & 0.65 & $0.59-0.70$ & $<0.001$ & 0.85 & $0.76-0.94$ & 0.002 \\
\hline No & 91.2 & & 20 , & & 1.00 & Referent & & 1.00 & Referent & \\
\hline Chemotherapy and tumor stage & & & & & & & & & & \\
\hline No consult, localized cancer & 84.4 & & 10 , & & 1.00 & Referent & & 1.00 & Referent & \\
\hline Had consult, localized cancer & 92.7 & & & & 2.36 & $2.14-2.59$ & $<0.001$ & 2.27 & $1.96-2.64$ & $<0.001$ \\
\hline No consult, regional cancer & 94.3 & & & & 3.09 & $2.60-3.67$ & $<0.001$ & 2.22 & $1.84-2.67$ & $<0.001$ \\
\hline Had consult, regional cancer & 95.7 & & & & 4.12 & $3.56-4.77$ & $<0.001$ & 3.41 & $2.83-4.11$ & $<0.001$ \\
\hline Surgeon's case volume in previo & year & Mean & & Univaria & e analy & & & ltivar & GEE analy & \\
\hline & & & & OR & $95 \%$ & $P$ & & & $95 \% \mathrm{CI}$ & $P$ \\
\hline Per 10 breast surgeries increase & & 52.3 & .9 & 1.05 & $1.04-1$ & $<0.0$ & & & $1.03-1.10$ & $<0.001$ \\
\hline Distance to designated center for & xceller & n breast Care & $(\mathrm{km})$ & & & & & & & \\
\hline Per $20 \mathrm{~km}$ increase & & 29.6 & 3.4 & 0.97 & $0.96-0$ & $<0.0$ & & & $0.94-0.97$ & $<0.001$ \\
\hline
\end{tabular}

$C I$ Confidence interval, $O R$ odds ratio, $E R$ emergency room, N/A missing or unavailable data, GEE generalized estimating equations, $P P$ value

${ }^{a}$ Included were patients who received a consultation for radiotherapy up to 1 year after diagnosis, as per guideline recommendations

${ }^{\mathrm{b}}$ Unadjusted associations were assessed using bivariate analysis between outcome and characteristics

c Multivariate logistic regression using a GEE model with an exchangeable working correlation (value of 0.019 ) to account for clustering of patients $(N=27,483)$ within physicians $(N=424)$ was used to assess associations between predictors adjusted for pre-existing conditions, residence, year of diagnosis, stage of tumor, and surgeon's specialty. The mean cluster size was 64.7 patients, range: 1-796

chemotherapy even after adjusting for clustering of patients within the same physician. This may imply that gaps in one aspect of $\mathrm{BC}$ care may increase the odds for gaps in other aspects of BC care such as RT consideration resulting in worse outcomes after a diagnosis of cancer for some patients and elevated health care spending. These gaps represent factors that are potentially modifiable. Implementation of electronic medical records-based tools
[42], increasing continuity of care and telemedicine [43] can help primary care providers keep track of recommended treatments tailed to each individual patient's health status and insure proper continuum of cancer care for his or her patients in a cost-effective manner. We further demonstrated that women who lived farther away from designated RT centers were significantly less likely to be considered for RT (4\% decrease for every $20 \mathrm{~km}$ 
increase in distance) after adjusting for other covariates. It is well known that women living further from RT centers have a lower likelihood of receiving RT [31], but an association between distance and lack of consideration suggests that distance might be a barrier not only to patients but also to physicians as well when it comes to providing a referral. During a self-administered survey of physician referral practices for hereditary breast cancer, conducted by Koil et al., rural-practice physicians reported several barriers including "distance of services," "lack of awareness of services," "lack of effective risk reduction or clinical management," and "patients not interested" $(P<0.05)$ [24]. Telemedicine could aid in providing referrals for RT to eligible patients, who currently do not get considered due to distance barriers.

Similar to other studies [22], we found that surgeons with higher volume of BCSs were significantly more likely to comply with guidelines and provide a consultation for RT compared to lower volume surgeons ( $7 \%$ increase for every 10 additional lumpectomies). We observed a similar relationship between high-volume centers and treatment outcomes (results not shown). Birkmeyer et al. [4] found that high-volume hospitals have better outcomes in large part because patients at these hospitals are more likely to be treated by high-volume surgeons and that standards based on surgeon volume as well as hospital volume would be more useful in directing patients to the providers who are likely to achieve the best outcomes. They hypothesized that improving surgeon's decision-making skills could simply be achieved by "practice" — clinical judgment and technical skill that are achieved only by surgeons who perform a specific procedure with sufficient frequency [4]. Harmon et al. [19] showed that medium-volume surgeons achieved results equivalent to high-volume surgeons when they operated in high- or medium-volume hospitals. Thus, high-volume hospitals could be allowing greater access to specialized teams in all aspects of patient care and the development of clinical pathways. Continuous education programs, redistribution of cases among a smaller number of surgeons in high-volume hospitals, and performance evaluations could ensure that surgeons meet certain practice-based competency levels or stay up to date with the most recent innovations in cancer care.

This study has several limitations. Similar to other studies that use administrative claims, there was no information on provider's reasoning or on tumor factors such as size of margins, histology grade, and the presence of comedo necrosis. The availability of prior data was not sufficient to allow us to control for patients with childhood Hodgkin Lymphoma, a contraindication for RT due to prior RT. However, given the low incidence rate of this disease in the Canadian population (3 per 100,000) [6], had we controlled for this, at most one patient would have been excluded. The CCI might underestimate the true patient comorbidity profile because the coding algorithm flags only diagnoses arising from comorbidities severe enough to result in medical service utilization. Nevertheless, this is the best proxy for this variable. Procedures not billed for by physicians by error and procedures performed at private clinics (an exception in Quebec) were missing. The strengths of our study lie in the fact that the entire population of women undergoing BCS in Quebec was captured and that the data are robust: physicians are paid on a feefor-service basis, and completeness and accuracy of reporting have monetary incentives attached [17].

\section{Conclusion}

We found that 1 in 10 women with high-risk, non-metastatic BC that underwent BCS in Quebec between 1998 and 2005 did not get considered for guideline-recommended RT. The younger and elderly women, socially isolated or those who lived far from designated RT centers, those with multiple comorbidities, hospital admissions, or ER visits in the past year were significantly less likely to be considered for RT. Women with stage III BC not considered for chemotherapy were also less likely to be considered for RT, suggesting that gaps in one aspect of cancer care quality may increase the odds of gaps in other aspects of treatment. Surgeon case volume in the previous year was associated with greater odds of RT consideration. Strengthening continuity of care and implementing tools such as electronic medical records and telemedicine could minimize some disparities and ensure timely delivery of care. Further investigation is required to better understand the relationship between surgeon volume and compliance with guidelines of care.

Acknowledgments The Canadian Cancer Society Research Institute (CCSRI), Canadian Institutes of Health Research (CIHR), and Fonds de la recherche en Santé du Québec (FRSQ) provided funding for this study.

Conflict of interest The authors have no conflict of interest to declare.

Open Access This article is distributed under the terms of the Creative Commons Attribution Noncommercial License which permits any noncommercial use, distribution, and reproduction in any medium, provided the original author(s) and the source are credited.

\section{Appendix}

See Tables 3 and 4 
Table 3 RAMQ Procedure codes

\begin{tabular}{|c|c|c|}
\hline Variable & RAMQ procedure code & Description \\
\hline BCS (i.e. lumpectomy) & 01174, 01175, 01201, 01204, 01205,01228, 01229 & Partial excision of breast \\
\hline Pregnancy & $\begin{array}{l}\text { 00910, 00911, 00921, 00923, 06900, 06902, 06903, } \\
\text { 06905, 06906, 06908, 06909, 06912, 06913, 06919, 06923, } \\
\text { 06924, 06938, } \\
\text { 06939, 06941, 06943, 06945, 06946, 06947, 06948, 06949, } \\
\text { 06950, 06951, 06952 }\end{array}$ & $\begin{array}{l}\text { Procedures related to the care of } \\
\text { pregnant women }\end{array}$ \\
\hline $\begin{array}{l}\text { Consultation for } \\
\text { chemotherapy }\end{array}$ & $\begin{array}{l}\text { 09127, 09165, 09129, 015000, 015001, 015002, 09150, 09160, } \\
\text { 09094, 09012, 09152, 015005, 015007, 015008, 015009, } \\
\text { 015010, } \\
\text { 09162, 09170, 09164, 015020, 015021, 015022, }\end{array}$ & $\begin{array}{l}\text { Procedures corresponding to } \\
\text { chemotherapy visit, consultation } \\
\text { or follow-up }\end{array}$ \\
\hline $\begin{array}{l}\text { Treatment with } \\
\text { chemotherapy }\end{array}$ & 0734 & Chemotherapy injection \\
\hline Consultation for RT & $\begin{array}{l}\text { 09060, 09078, 09080, 09127, 09150, 09152, 09160, } 09162 \text {, } \\
\text { 09164, 09165, 09170, 09171, 09129 }\end{array}$ & $\begin{array}{l}\text { Procedures corresponding to consultation } \\
\text { between patient and radiation therapist }\end{array}$ \\
\hline Treatment with RT & $\begin{array}{l}\text { 08520, 08519, 09131, 09133, 09134, 09141, 09143, 09144, } \\
\text { 09146, 09172, 08507, 08508, 08509, 08511, 08553, 08564, } \\
08518\end{array}$ & $\begin{array}{l}\text { Procedures corresponding to the provision of RT } \\
\text { treatments }\end{array}$ \\
\hline
\end{tabular}

Table 4 ICD-9-QC Codes

\begin{tabular}{llc}
\hline Variable & ICD-9-QC code & Description \\
\hline BC & 174 & Malignant neoplasm of female breast \\
diagnosis & & $\begin{array}{c}\text { Codes corresponding to conditions related to } \\
\text { diffuse connective tissue disease }\end{array}$ \\
DCTD & $695.4,701.0,710.0,710.1,710.2,710.3,710.4,710.8,710.9$ & Codes corresponding to various pulmonary \\
& & \\
COPD & $416.8,416.9,490.0,490.9,491.0,491.1,491.2,491.8,491.9,492.0,492.9,493.0$, & conditions \\
& $493.1,493.9,494.0,494.9,495.0,495.1,495.2,495.3,495.4,495.5,495.6,495.7$, & \\
& $495.8,495.9,496.0,496.9,500.0,500.9,501.0,501.9,502.0,502.9,503.9,504.0$, & \\
& $504.9,505.0505 .9,506.4,508.1,508.8$ & \\
\hline
\end{tabular}

\section{References}

1. Amichetti M, Vidali C (2012) Radiotherapy after conservative surgery in ductal carcinoma in situ of the breast: a review. Int $\mathbf{J}$ Surg Oncol 2012:635404

2. Ballard-Barbash R, Potosky AL, Harlan LC, Nayfield SG, Kessler LG (1996) Factors associated with surgical and radiation therapy for early stage breast cancer in older women. J Natl Cancer Inst 88:716-726

3. Bickell NA, Wang JJ, Oluwole S, Schrag D, Godfrey H, Hiotis K, Mendez J, Guth AA (2006) Missed opportunities: racial disparities in adjuvant breast cancer treatment. J Clin Oncol 24:1357-1362

4. Birkmeyer JD, Stukel TA, Siewers AE, Goodney PP, Wennberg DE, Lucas FL (2003) Surgeon volume and operative mortality in the United States. N Engl J Med 349:2117-2127

5. Bleyer A (2007) Young adult oncology: the patients and their survival challenges. CA Cancer J Clin 57:242-255

6. Canadian Cancer Society and Statistics Canada (2012) Canadian cancer statistics. Canadian Cancer Society, Toronto, ON. www. cancer.ca. Accessed 6 Dec 2012

7. Chagpar AB, McMasters KM, Scoggins CR, Thoene C, Edwards MJ (2008) The use of radiation therapy after breast-conserving surgery in hormonally treated breast cancer patients is dependent on patient age, geographic region, and surgeon specialty. Am J Surg 195:793-798

8. Chen F, Puig M, Yermilov I, Malin J, Schneider EC, Epstein AM, Kahn KL, Ganz PA, Gibbons MM (2011) Using breast cancer quality indicators in a vulnerable population. Cancer 117:3311-3321. doi:10.1002/cncr.25915

9. Clarke M, Collins R, Darby S, Davies C, Elphinstone P, Evans E, Godwin J, Gray R, Hicks C, James S (2005) Effects of radiotherapy and of differences in the extent of surgery for early breast cancer on local recurrence and 15-year survival: an overview of the randomised trials. Lancet 366:2087

10. D'Hoore W, Bouckaert A, Tilquin C (1996) Practical considerations on the use of the Charlson comorbidity index with administrative data bases. J Clin Epidemiol 49:1429-1433

11. Dragun AE, Huang B, Tucker TC, Spanos WJ (2011) Disparities in the application of adjuvant radiotherapy after breast-conserving surgery for early stage breast cancer. Cancer 117:2590-2598. doi:10.1002/cncr.25821

12. EBCTCG (2005) Effects of chemotherapy and hormonal therapy for early breast cancer on recurrence and 15-year survival: an overview of the randomised trials. Lancet 365:1687-1717. doi:10.1016/S0140-6736(05)66544-0

13. Emdin SO, Granstrand B, Ringberg A, Sandelin K, Arnesson LG, Nordgren H, Anderson H, Garmo H, Holmberg L, Wallgren A 
(2006) SweDCIS: radiotherapy after sector resection for ductal carcinoma in situ of the breast. Results of a randomised trial in a population offered mammography screening. Acta Oncol 45:536-543. doi:10.1080/02841860600681569

14. Enterline PE, Salter V, McDonald AD, McDonald JC (1973) The distribution of medical services before and after free medical care-the Quebec experience. N Engl J Med 289:1174-1178

15. Fisher B, Redmond C, Poisson R, Margolese R, Wolmark N, Wickerham L, Fisher E, Deutsch M, Caplan R, Pilch Y et al (1989) Eight-year results of a randomized clinical trial comparing total mastectomy and lumpectomy with or without irradiation in the treatment of breast cancer. N Engl J Med 320:822-828. doi:10.1056/NEJM198903303201302

16. Fisher B, Anderson S, Bryant J, Margolese RG, Deutsch M, Fisher ER, Jeong JH, Wolmark N (2002) Twenty-year follow-up of a randomized trial comparing total mastectomy, lumpectomy, and lumpectomy plus irradiation for the treatment of invasive breast cancer. N Engl J Med 347:1233-1241. doi:10.1056/ NEJMoa022152347/16/1233

17. Fortin B, Goldberg MS, Mayo NE, Valois MF, Scott SC, Hanley J (2006) Waiting time for radiation therapy in breast cancer patients in Quebec from 1992 to 1998: a study of surgically treated breast cancer patients in Quebec documents and helps to explain increased waiting times for radiation therapy. Health Policy 1:152-167

18. Government of Quebec Designated referral centres (CRIDs) (2012) http://www.msss.gouv.qc.ca/sujets/santepub/pqdcs/index. php?crid_en. Accessed 18 Sept 2012

19. Harmon JW, Tang DG, Gordon TA, Bowman HM, Choti MA, Kaufman HS, Bender JS, Duncan MD, Magnuson TH, Lillemoe KD (1999) Hospital volume can serve as a surrogate for surgeon volume for achieving excellent outcomes in colorectal resection. Ann Surg 230:404

20. Harper S, Lynch J, Meersman SC, Breen N, Davis WW, Reichman MC (2009) Trends in area-socioeconomic and race-ethnic disparities in breast cancer incidence, stage at diagnosis, screening, mortality, and survival among women ages 50 years and over (1987-2005). Cancer Epidemiol Biomarkers Prev 18:121-131. doi:10.1158/1055-9965.EPI-08-0679

21. Hershman DL, Kushi LH, Shao T, Buono D, Kershenbaum A, Tsai W-Y, Fehrenbacher L, Gomez SL, Miles S, Neugut AI (2010) Early discontinuation and nonadherence to adjuvant hormonal therapy in a cohort of 8,769 early-stage breast cancer patients. J Clin Oncol 28:4120-4128

22. Hillner BE, Smith TJ, Desch CE (2000) Hospital and physician volume or specialization and outcomes in cancer treatment: importance in quality of cancer care. J Clin Oncol 18:2327-2340

23. Jagsi R, Abrahamse P, Morrow M, Hawley ST, Griggs JJ, Graff JJ, Hamilton AS, Katz SJ (2010) Patterns and correlates of adjuvant radiotherapy receipt after lumpectomy and after mastectomy for breast cancer. J Clin Oncol 28:2396-2403

24. Koil CE, Everett JN, Hoechstetter L, Ricer RE, Huelsman KM (2003) Differences in physician referral practices and attitudes regarding hereditary breast cancer by clinical practice location. Genet Med 5:364-369

25. Landercasper J, Dietrich LL, Johnson JM (2006) A breast center review of compliance with national comprehensive cancer network breast cancer guidelines. Am J Surg 192:525-527. doi:10. 1016/j.amjsurg.2006.05.012

26. Liang KY, Zeger SL (1986) Longitudinal data analysis using generalized linear models. Biometrika 73:13-22

27. Malin JL, Schuster MA, Kahn KA, Brook RH (2002) Quality of breast cancer care: what do we know? J Clin Oncol 20:4381-4393

28. Mayo NE, Scott SC, Shen N, Hanley J, Goldberg MS, MacDonald N (2001) Waiting time for breast cancer surgery in Quebec. Can Med Assoc J 164:1133-1138
29. McCusker J, Tousignant P, Da Silva RB, Ciampi A, Lévesque J-F, Vadeboncoeur A, Sanche S (2012) Factors predicting patient use of the emergency department: a retrospective cohort study. Can Med Assoc J 184:E307-E316

30. Murphy MM, Tseng JF, Shah SA (2010) Disparities in cancer care: an operative perspective. Surgery 147:733-737. doi:10. 1016/j.surg.2009.10.050

31. Nattinger AB, Kneusel RT, Hoffmann RG, Gilligan MA (2001) Relationship of distance from a radiotherapy facility and initial breast cancer treatment. J Natl Cancer Inst 93:1344-1346

32. NCCN National Comprehensive Cancer Network: Clinical Practice Guidelines in Oncology. Breast Cancer, version 1.2012

33. Olivotto A, Coldman AJ, Hislop TG, Trevisan CH, Kula J, Goel V, Sawka C (1997) Compliance with practice guidelines for node-negative breast cancer. J Clin Oncol 15:216-222

34. Olivotto I, Levine M (2001) Clinical practice guidelines for the care and treatment of breast cancer: the management of ductal carcinoma in situ (summary of the 2001 update). Cmaj 165:912-913

35. Pampalon R, Hamel D, Gamache P, Raymond G (2009) A deprivation index for health planning in Canada. Chronic Dis Can 29:178-191

36. Quan H, Sundararajan V, Halfon P, Fong A, Burnand B, Luthi JC, Saunders LD, Beck CA, Feasby TE, Ghali WA (2005) Coding algorithms for defining comorbidities in ICD-9-CM and ICD-10 administrative data. Med Care 43:1130-1139

37. Roetzheim RG, Gonzalez EC, Ferrante JM, Pal N, Van Durme DJ, Krischer JP (2000) Effects of health insurance and race on breast carcinoma treatments and outcomes. Cancer 89:2202-2213. doi:10.1002/1097-0142(20001201)89:11<2202:AID-CNCR8>3. $0 . \mathrm{CO} ; 2-\mathrm{L}$

38. Sacerdote C, Bordon R, Pitarella S, Mano MP, Baldi I, Casella D, Di Cuonzo D, Frigerio A, Milanesio L, Merletti F (2013) Compliance with clinical practice guidelines for breast cancer treatment: a population-based study of quality-of-care indicators in Italy. BMC Health Serv Res 13:28

39. Smith GL, Shih YCT, Xu Y, Giordano SH, Smith BD, Perkins GH, Tereffe W, Woodward WA, Buchholz TA (2010) Racial disparities in the use of radiotherapy after breast-conserving surgery: a national Medicare study. Cancer 116:734-741

40. Srokowski TP, Fang S, Duan Z, Buchholz TA, Hortobagyi GN, Goodwin JS, Giordano SH (2008) Completion of adjuvant radiation therapy among women with breast cancer. Cancer 113:22-29

41. Statistics Canada Glossary: Rural Delivery Area (2012) http:// www.statcan.gc.ca/pub/92f0138m/2007001/4054931-eng.htm. Accessed 18 Sept 2012

42. Steinberg ML (2008) Inequity in cancer care: explanations and solutions for disparity. Semin Radiat Oncol 18:161-167

43. The American Telemedicine Association (ATA) Telemedicine Defined (2012) http://www.americantelemed.org/i4a/pages/ index.cfm?pageid=3333. Accessed 18 Sept 2012

44. Tyldesley S, Zhang-Salomons J, Groome PA, Zhou S, Schulze K, Paszat LF, Mackillop WJ (2000) Association between age and the utilization of radiotherapy in Ontario. Int $\mathrm{J}$ Radiat Oncol Biol Phys 47:469-480

45. Veronesi U, Salvadori B, Luini A, Greco M, Saccozzi R, del Vecchio M, Mariani L, Zurrida S, Rilke F (1995) Breast conservation is a safe method in patients with small cancer of the breast. Long-term results of three randomised trials on 1,973 patients. Eur J Cancer 31A:1574-1579

46. Ward E, Halpern M, Schrag N, Cokkinides V, DeSantis C, Bandi P, Siegel R, Stewart A, Jemal A (2008) Association of insurance with cancer care utilization and outcomes. CA Cancer J Clin 58:9-31. doi:10.3322/CA.2007.0011

47. Wheeler SB, Wu Y, Meyer AM, Carpenter WR, Richardson LC, Smith JL, Lewis MA, Weiner BJ (2012) Use and timeliness of radiation therapy after breast-conserving surgery in low-income women with early-stage breast cancer. Cancer Invest 30:258-267 